International Journal of Engineering \& Technology, $7(4.11)(2018) 95-98$
International Journal of Engineering \& Technology
SPC
Website: www.sciencepubco.com/index.php/IJET
Research paper

\title{
Identifying High Impact Disaster Triggers on Computer Networks in Asia Pacific Region
}

\author{
Rabab Alayham Abbas Helmi ${ }^{1 *}$, Arshad Jamal ${ }^{2}$, Marwan Abdul Hameed Ashour ${ }^{3}$ \\ ${ }^{I}$ Faculty of Information Sciences and Engineering, Management and Science University, Malaysia \\ ${ }^{2}$ Faculty of Information Sciences and Engineering, Management and Science University, Malaysia \\ ${ }^{3}$ College of Administration and Economics, University of Baghdad, Iraq \\ *Corresponding author E-mail: rabab_alayham@msu.edu.my
}

\begin{abstract}
This paper aims to study various aspects of Asia Pacific region in order to identify the most common disasters as well as disasters with the largest impact. It represents a first step in developing a strategy to face topological network failure that is triggered by an accidental disaster. The study of Asia-Pacific region is crucial, firstly because in order to properly address a problem it is very important to properly define the problem at hand and its surroundings. Secondly, because disasters include in their impacts various aspects of the society those aspects have their own further effect on the society, therefore, it is of great importance to address all aspects of the region that can have a cross effect with disasters. The main focus in this paper is this cross effect with computer network infrastructure; due to their important role in the society's way of life, as well as their fatal role during disasters and crisis.
\end{abstract}

Keywords: Asia-Pacific; Disaster Preparedness; Modeling; Regional Network Failure; Topological Network Failure.

\section{Introduction}

Asia-Pacific region has high disasters' vulnerability. It has witnessed two disasters of huge caliber in recent years. After any disaster, there is a noticeable increase in disaster work that mainly focuses on the disasters impact area, on that type of disaster and on the significant key impact factor. Asia-Pacific is not an exception. After the major disasters that hit the region, the amount of attention to addressing disasters in the region increased dramatically. This resulted in making addressing disaster in the region a priority for governments, aid organization and the United Nations. As a matter of fact, some disasters in the region were actually a significant milestone or even turning point for disaster management and disaster studies in the whole world [1].

The term Asia Pacific region refers to a number of countries that have come together in a number of treaties, agreements, understandings and regional organizations and bodies in order to achieve common goals. But, mostly to face common threats, one of the major threats that face the region are disasters. The region consists of a number of bodies charged with coordinating countries in sub-regions as following:

- Association of Southeast Asian Nations (ASEAN).

- South Asia Association for Regional Cooperation (SAARC).

- $\quad$ Pacific Islands Forum (PIF).

- Secretariat of the Pacific Community (SPC).

- $\quad$ East Asia Summit (EAS)

- Asia Pacific Economic Cooperation (APEC).

There are also a number of organizations that work on disasters in the region such as the regional organizations; for example, the ASEAN Coordinating Centre for Humanitarian Assistance on disaster management (AHA Centre). Meanwhile, the main UN agencies with humanitarian mandates support disaster response across needs, from shelter, protection, food security, health, nutrition, education and livelihoods to common services like coordination, logistics and telecommunications. Other nongovernmental organizations like the International Federation of Red Cross and Red Crescent Societies (IFRC) and International Committee of the Red Cross (ICRC) the region countries share a number of regional inherited similarities. At the same time, a number of differences between the region countries exist [2]. This needs addressing to better understand the disasters theater before discussing disaster's impact. This paper covers studying the region in terms of; geographical nature, population, disaster preparedness, vulnerability, disasters and computer networks. As a result, the most frequent disasters in the region are identified, as well as the disasters that have the greatest regional impact are identified.

\section{Literature Review}

\subsection{Asia-Pacific Region's Geography}

Although the region is out spared on a large geographical area, but this area is mostly covered with water surfaces like seas and ocean with many islands within the region. Making connecting different parts a challenging task and at the same time increase routes options, but increase the possibilities of hydrological disasters.

The metrological nature of the region is diverse. It includes different weather types, diverse temperature ranges, different rain and drought seasons and different types of storms and typhoons to handle. The region also includes one of the largest rain forests in the world. This is another challenge when it comes to infrastructures, transportation, evacuations and supplies routes. 


\subsection{Population and Disaster Preparedness}

The region has some of the most disaster prepared societies and nations, where disaster preparedness is an everyday routine for the general population, and disaster awareness starts from very early ages. Those countries also have the enabling infrastructure that is combined with high survivability for it.

At the same time, there is another fact to be considered that is the poverty rate in some of the region countries are so high making the population more affected by disasters' impacts and the weak basic structures proves to be an obstacle for relief efforts after disaster hits. The ADPC overview on disaster management [3] declares that countries with weak economy and high poverty rates are more effected by disasters, and that the population there has lower ability to cope with disasters' impacts.

The impact of disasters on developing economies can be parallelizing since in some situations the disaster's cost or losses is higher than the total annual output of that economy, meaning that disasters can damage more than what the economy can produce in a year. Therefore, crippling the country and slowing if not halting development. Once again, the economy and infrastructure in the region is diverse, this is another reason for careful planning for both preparedness and response.

\section{Results and Discussion}

\subsection{Asia Pacific Disasters' Vulnerability}

There is no argument that Asia Pacific region is the most prone to disasters in the world as stated by the United Nations on many publications, press releases and on organization official web sites. Fig. 1 shows the number of natural disasters' events in different regions for 30 years. It clearly indicated that Asia Pacific has the highest rate throughout the 30 years with no other region close to it. Another fact to notice in the same figure is that the region number of events is not only the highest, but it also increased the most [4].

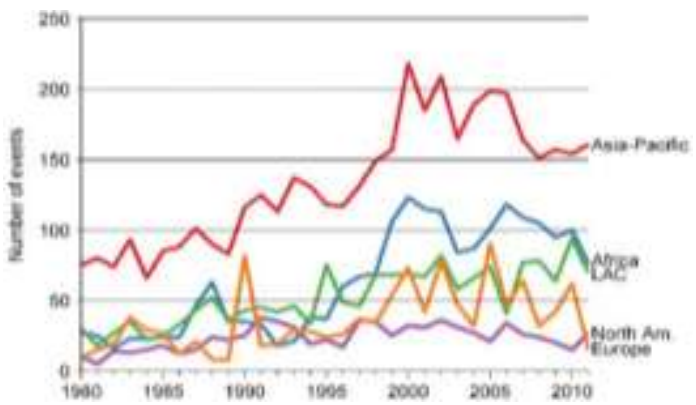

Fig. 1: Number of Natural Disasters Events in Regions of the World [4]

Naturally, if the number of disasters is high, so will be the effected people, this is shown in Fig. 2. The figure shows the number in millions of people affected by disasters every year in different regions. The countries that are more affected by disasters based on population income are presented in Fig. 3. The figure shows the average annual impact income classification 2002 - 2012. The figure clearly shows that low-income countries are much more affected by disasters impact than middle and high-income countries. This information in this figure concurs with the previous section statement regarding the impact of poverty on disaster preparedness and recovery.

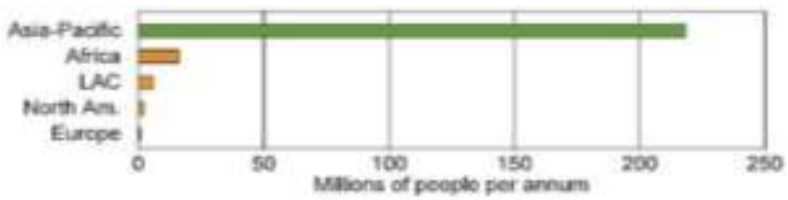

Fig. 2: People Affected by Natural Disasters Per-Year [4]

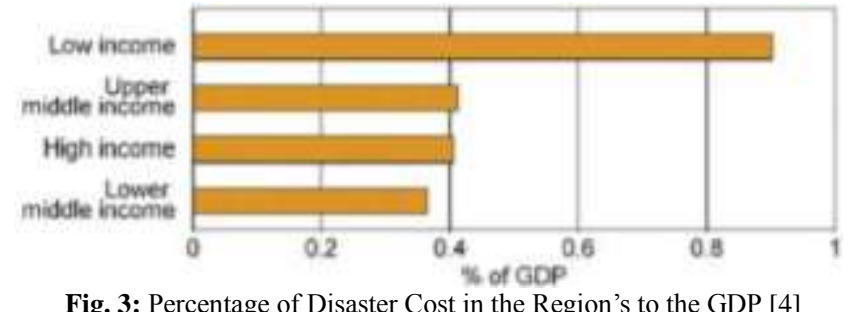

Fig. 3: Percentage of Disaster Cost in the Region's to the GDP [4]

\subsection{Disasters in Asia Pacific Region}

During the near history Asia-Pacific region has witnessed some of the deadliest, largest and most costing disasters in history, a part from the fact that the region receive the biggest share of disasters in the world and that the population there are the most effected with disasters. The most devastating disasters seem to take place there as well. This is clear when considering the losses disasters cost; the statistics in [4] shows clearly the difference in losses cost between Tohoku 2011 disaster and others such as the Katrina Storm. In terms of magnitude, out of top five earthquakes in history two happened in this region, it has also some of the most devastating floods and storms. As a result, the number of natural disasters' casualties per year is the highest in the region. Fig. 4 shows the number of people killed in each region in thousands per year [5].

However, the answer is in planning and preparedness. It has been shown in the cases of countries like Japan, Indonesia and the Philippines where money spent on reducing the risk of natural hazards is a sound investment and those countries have managed to achieve lower human as well as economical losses because of disasters after taking positive steps in disaster mitigation. A UNDP study shows that for every dollar spent on disasters' preparedness, saves seven dollars in after disaster response.

Floods and storms trigger the most common disasters in the region, but highest impact and biggest losses comes from earthquakes and tsunamis. Other disasters such as mud slides and health disasters also happen in the region, but their effect is mostly localized. Therefore, it is concluded that earthquakes and their escalations are the most effective triggers in the region, next to the effects triggers by floods [4].

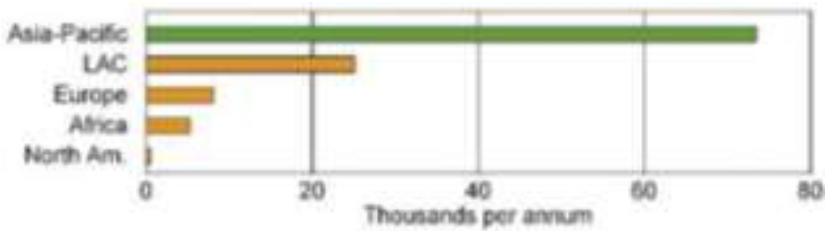

Fig. 4: Regional Disaster Fatalities [4]

This conclusion is confirmed with disaster impact information from Indonesia [6]. The online database includes the impact information of each type of disasters in terms of victims and destruction. The database includes all recorded disasters in Indonesia, starting from 1815 and up to date. Table 1 shows impact information for selected disasters from the online database. The table shows the impact information for accidental disasters with the highest impact only. The number of casualties and injured represent the humane loss impact and the economic loss is represented by the number of houses destroys and damaged. The information that represents the impact of all disasters' triggers on the country can be found in the mentioned online database.

To further illustrate the impact of the highest affecting disasters which are caused by accidental triggers, the data from Table 1 is classified using bar-graphs. The information regarding human loss representation is shown is Fig. 5, it is clear from the figure that most deaths from disasters are caused by floods, but if we combine earthquake and tsunami and earthquake deaths it has higher mortality rate. Moreover, the floods are more frequent, therefore 
the summation of their effect seems larger but the impact of earthquakes and their escalations is in fact larger. This is shown in graphical representation in the database [6] and confirmed in the findings in [4].

The monetary losses impact information is illustrated in Fig. 6. This type of disaster impact is clearly higher in earthquakes and their escalation then in floods. The information from the table and both figures are clear confirmation of the earlier conclusion that earthquakes are their escalations like tsunamis are the disaster triggers with the highest impact in the region. This is applicable for the region as a whole, and for individual countries. It is one of the inherited characteristics of disaster impact in the region.

Table 1: Accidental Disasters' Triggers Impact in Indonesia [6]

\begin{tabular}{|c|c|c|c|c|c|}
\hline Event & Deaths & Injured & Missing & Houses Destroyed & Houses Damaged \\
\hline Earthquake & 15518 & 72225 & 1513 & 500223 \\
\hline Earthquake and Tsunami & 167779 & 3988 & 6333 & 324908 \\
\hline Eruption & 78627 & 3603 & 7 & 402 & 125307 \\
\hline Floods & 18891 & 194994 & 2542 & 4221 \\
\hline Floods and Landslides & 2300 & 40803 & 5365 & 977 \\
\hline Forest Fire & 13 & 13483 & 0 & 92835 \\
\hline Landslides & 2309 & 2315 & 192 & 9587 \\
\hline
\end{tabular}

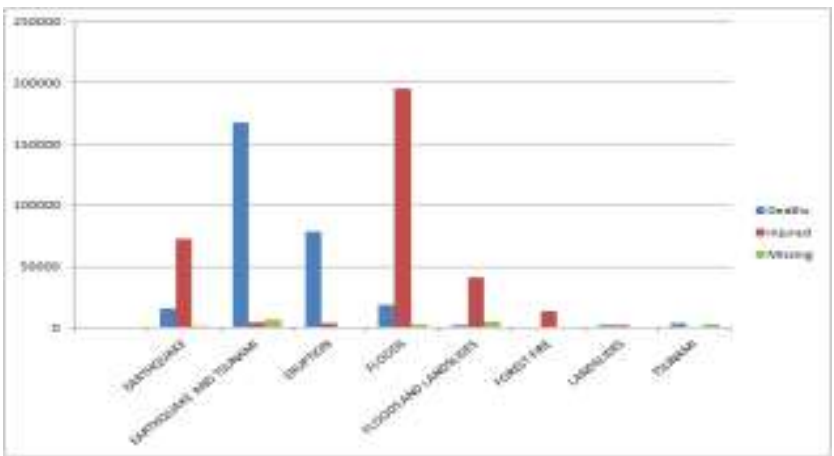

Fig. 5: Indonesia’s Disasters' Impact- Human Loss

\section{Asia Pacific Networks}

Computer networks are becoming increasingly important and their failures are becoming costlier due to the large dependence on them in everyday life, thus increasing the importance of insuring a highly survivable network. Since disasters are highly unavoidable events and since even resilient and well-managed networks can still be affected by a failure in the regional network that is caused by a geographically related failure like an accidental disaster, it is important to plan for such events [7].

Moreover, the important of networks and their role is enhanced considerably during disasters. This is because disaster management highly depends on networks in aspects like coordination, notification, evacuation instruction, victim locating and logistics. Therefore, it is very important to consider networks as part of the vital infrastructures for the purpose of disaster planning in all its stages [8].

The region geographical location gives it great importance in term of location, it is a region that connects other parts of the world. As it includes most of the countries overlooking the Pacific Ocean, it has full access to one of the largest water covered surfaces on earth. As a result, most of communications' connections' cabling use undersea cables.

The same situation is inherited by IP networks. The maps in Fig. 7 shows the Australian IP network map and Fig. 8 shows the Asia's global IP network map. Both maps complement each other for full view of the regional network. From observing both maps, a number of conclusions are made. First is that the region networks control almost all trans-pacific connections to the USA [9]. Second is that most of the region is well connected with undersea cables which increase vulnerability and third is the conclusion that there are some parts of the region are not well connected. Although some parts are connected, but they are end point with a single route that increase the vulnerability even more. The region is served by a number of service providers and is likely to witness more service in the future.

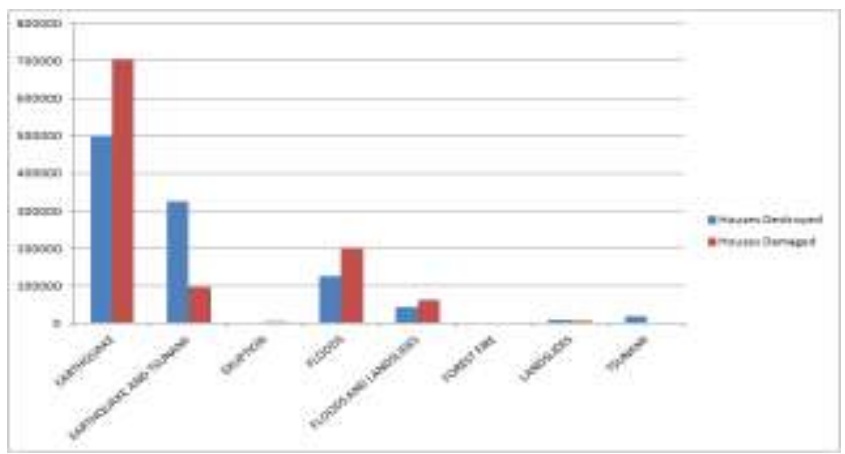

Fig. 6: Indonesia's Disasters' Impact- Monetary Loss

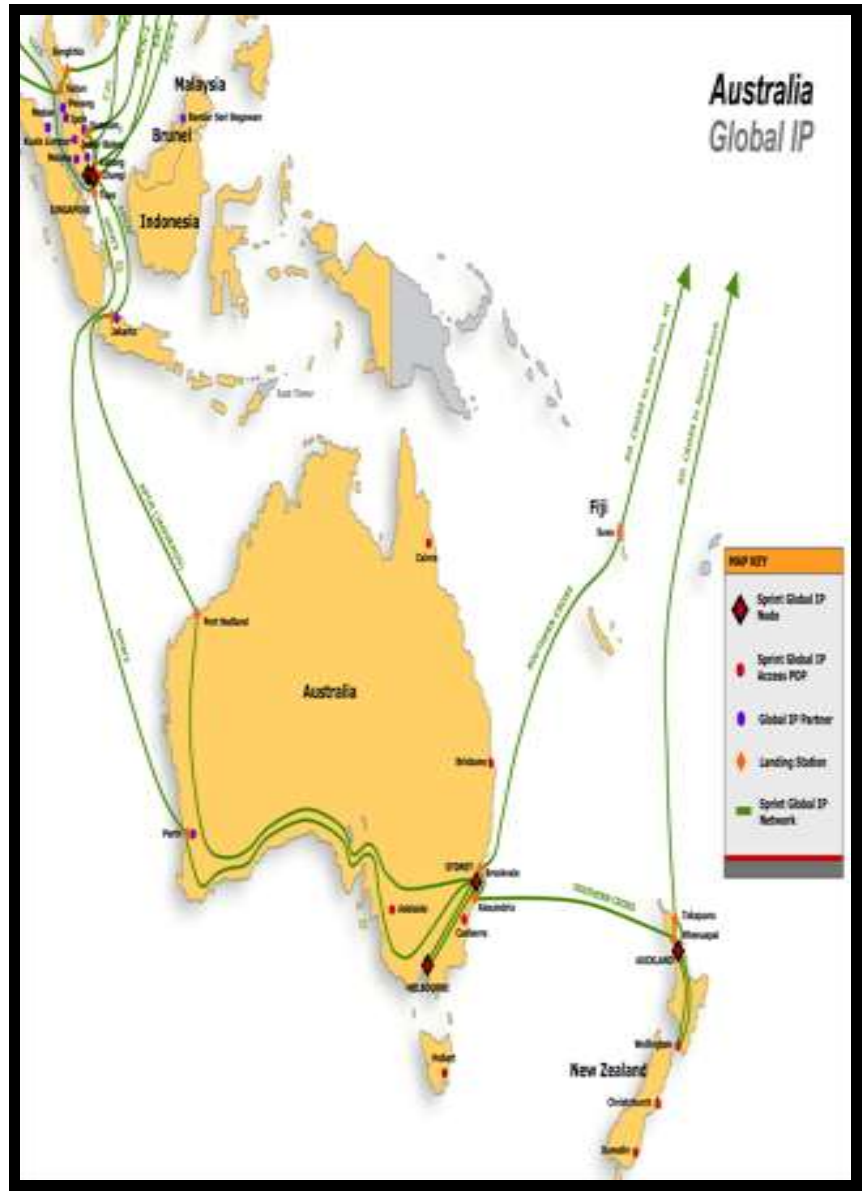

Fig. 7: Global IP Networks -Australia [10] 


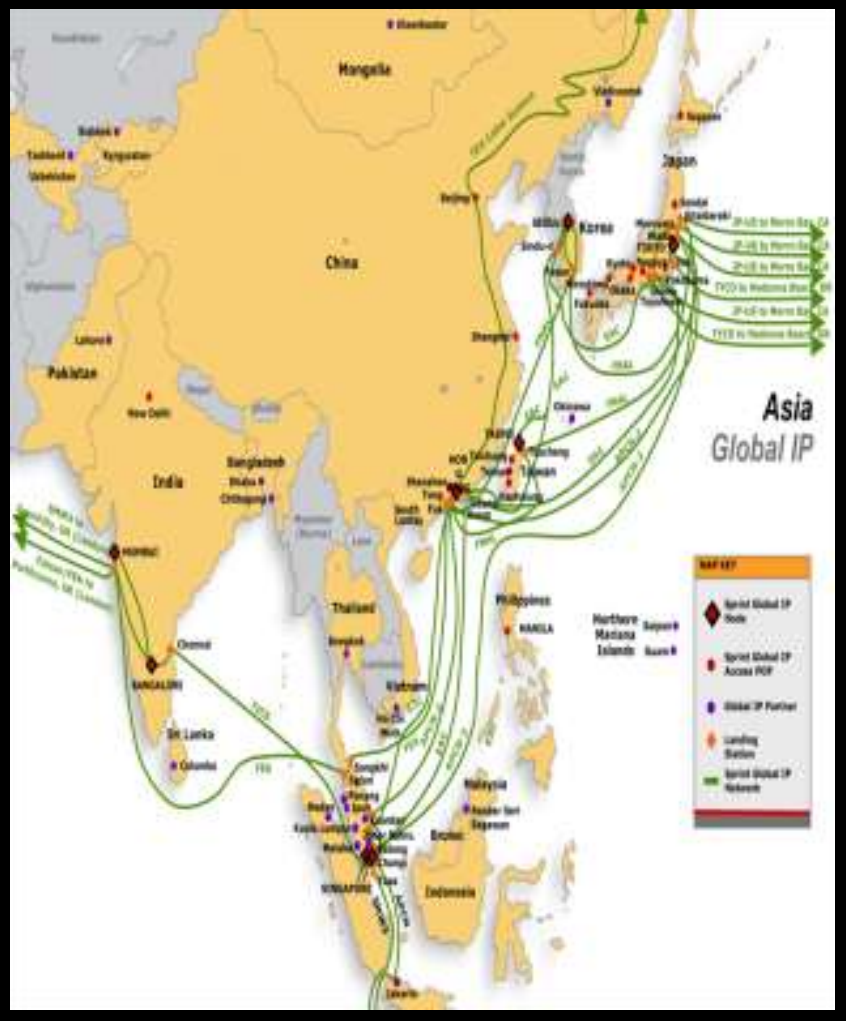

Fig. 8: Global IP Networks - South Asia [10]

\section{Conclusion}

Through the information presented in this paper, the first and most important finding is the urgent need for a plan to face disasters in Asia Pacific region. Firstly, it is because the region is highly prone to accidental disasters and secondly is because the disaster threat is increasing. This will increase is visible in both the frequency of disasters and its complexity. Such plan needs to include a great amount of focus on disaster preparedness due to the geographical and social regional factors.

The disaster history in the region shows that the most frequent disasters' triggers in the region are flood, but the biggest disaster impact comes from disasters triggered by earthquakes as well as earthquakes which can cause other triggers. This conclusion is true for the region as a whole and is also true for countries in the region when considered individually.

As for network topology, it is an important part of the infrastructure that enables the current societies way of life. Networks in the region are important to insure connectivity. This is due to the large water surfaces the region includes. It is also important in connecting other parts of the world. Therefore, it is important to study the impact of disasters that are initially triggered by earthquakes. This study need to include different disaster scenarios in order to sketch a strategy that can be followed in planning for survivable networks for a region.

\section{References}

[1] H. Rodríguez, E. L. Quarantelli, R. R. Dynes, E. L. Quarantelli, P. Lagadec, and A. Boin, "A heuristic approach to future disasters and crises: New, old, and in-between types. In Handbook of Disaster Research. New York: Springer, pp. 16-41, 2007.

[2] U. OHCHR, "Disaster response in Asia and the Pacific: A guide to international tools and services," 2011, https://www.unocha.org/sites/unocha/files/ROAP_DisasterGuide.pd f.

[3] M. L. Bildan, Disaster management in Southeast Asia: An overview. 2003 ,
http://www.adpc.net/v2007/IKM/ONLINE\%20DOCUMENTS/dow nloads/11-DMSEA.PDF

[4] ESCAP, "Statistical yearbook for Asia and the Pacific 2013," 2013 , https://www.unescap.org/sites/default/files/publications/ESCAPSYB2013-full.pdf.

[5] UNISDR, "Reducing vulnerability and exposure to disasters: The Asia-Pacific Disaster report 2012," 2012, https://www.unisdr.org/files/29288_apdr2012finallowres.pdf.

[6] A. Muhajir, and A. B. Cahyono, "Analisa persebaran bangunan evakuasi bencana tsunami menggunakan Network Analyst di SIG," Jurnal Teknik Pomits, 2(1), 1-6, 2013.

[7] R. A. Abbas, M. R. Mokhtar, R. Sulaiman, Z. A. Othman, and A. M. Zin, "Impact of disasters in Southeast Asia on Malaysian computer networks," Journal of Theoretical and Applied Information Technology, 37, 188-198, 2012.

[8] A. Kwasinski, "Analysis of vulnerabilities of telecommunication systems to natural disasters," 4th Annual IEEE Systems Conference, pp. 359-364, 2010

[9] [9] J. T. Araújo and K. Fukuda, "MALAWI: Aggregated longitudinal analysis of the MAWI dataset," Proceedings of the ACM CoNEXT Student Workshop, pp. 1-2, 2011.

[10] [10] TelecomRamblings, Telecom ramblings. 2008, http://www.telecomramblings.com 